\title{
Serum strain-specific or cross-reactive neuraminidase inhibiting antibodies against pandemic A/California/07/2009(H1N1) influenza in healthy volunteers
}

Yulia A Desheva*, Tatiana A Smolonogina, Svetlana A Donina and Larisa G Rudenko

\begin{abstract}
Background: Pre-existing antibodies to influenza virus neuraminidase may provide protection against infection influenza viruses containing novel hemagglutinin (HA). The aim of our study was to evaluate serum neuraminidase-inhibiting (NI) antibodies against A/California/07/2009(H1N1) [H1N1/2009pdm] and A/New Caledonia/20/1999(H1N1) [H1N1/1999] influenza viruses in relation with the age of participants and hemagglutination-inhibition (HI) antibody levels. Anti-H1N1/2009pdm neuraminidase and anti-H1N1/1999 neuraminidase antibody levels were measured in total 219 serum samples from Russian healthy peoples of various ages examined before and a year after pandemic strain appearance. We adjusted peroxidase-linked lectin micro-procedure to measure $\mathrm{NI}$ antibody titers using the reassortant $\mathrm{A} / \mathrm{H} 7 \mathrm{~N} 1$ influenza viruses based on A/equine/Prague/1/56(H7N7). Also, HI antibody titers were estimated against H1N1/2009pdm, H1N1/1999 and a panel of seasonal A/H1N1 influenza viruses.

Results: In sera samples collected during the fall of 2010, mean titers of specific $\mathrm{HI}$ and NI antibodies to H1N1/ 2009pdm were 2-2.1 times lower than antibody levels against H1N1/1999. Of the 163 individuals examined, 58 (35.6\%) had NI anti-H1N1/2009pdm antibody titers > 1:20, compared to 93 (57.1\%) who had NI anti-H1N1/1999 antibody titers $>1: 20$. There were low correlations between $\mathrm{HI}$ and $\mathrm{NI}$ antibody levels against either H1N1/1999 or H1N1/2009pdm in the same serum samples. The 24 adults born between 1957 and 1977 expressed very low levels of $\mathrm{Nl}$ antibodies to A/H1N1 influenza viruses. Persons with low HI anti-H1N1/2009pdm titers but positive to seasonal A/H1N1 demonstrated significantly higher NI anti-A/H1N1 antibody titers than unexposed subjects. In 2005 cross-reactive $\mathrm{NI}$ anti-H1N1/2009pdm antibody titers > 1:20 were detected among 7.1\% of young people.

Conclusions: Our study confirmed that contact with seasonal influenza viruses may have contributed to generating the cross-reacting anti-H1N1/2009pdm NI antibodies which were detected in the sera of 18-20 years old people examined before the pandemic virus active circulation. The lowest levels of antibodies to the neuraminidase of $\mathrm{N} 1$ subtype were in the group of participants born during the circulation of influenza A/H2N2 or $\mathrm{A} / \mathrm{H} 3 \mathrm{~N} 2$ viruses. The low correlation between $\mathrm{HI}$ and $\mathrm{NI}$ antibody titers suggests that $\mathrm{NI}$ antibody detection can be used as an additional test to evaluate the immune response after influenza infections or immunizations.
\end{abstract}

Keywords: Influenza virus, Neuraminidase, Anti-neuraminidase antibodies, Pandemic influenza, A/H1N1

\footnotetext{
* Correspondence: desheva@mail.ru

Institute of Experimental Medicine, Russian Academy of the Medical

Sciences, Acad. Pavlov's Street, 12, Saint Petersburg 197376, Russian

Federation
} 


\section{Background}

In April 2009, the World Health Organization registered the first 21st century pandemic caused by a type A/ H1N1 influenza virus (the genus Influenzavirus, the family Orthomyxoviridae) not previously isolated from animals or humans. Pandemic influenza, in contrast to seasonal influenza, affected young people more frequently than elderly [1]. In the USA, 79\% of laboratory-confirmed cases of pandemic H1N1/2009pdm infections were from persons younger than 30 years, and $2 \%$ from age group older than 60 years [2]. A number of publications have analyzed pre-existing neutralizing antibodies and T-cell immunity against $\mathrm{H} 1 \mathrm{~N} 1 / 2009 \mathrm{pdm}$ [2,3], although little is known about pre-existing cross-reactive anti-neuraminidase (NA), or neuraminidase-inhibiting (NI) antibodies to pandemic $\mathrm{A} / \mathrm{H} 1 \mathrm{~N} 1$ in humans. Several animal studies, including a plasmid DNA vaccine model, suggest that NI antibodies could provide partial protection from lung infection and even from lethal challenge with highly pathogenic $\mathrm{A} / \mathrm{H} 5 \mathrm{~N} 1$ influenza viruses [4-7].

In humans, NI antibodies play a role in decreasing the severity of natural infection caused by influenza A shift or drift variants [8]. Previously it was shown that immunization with seasonal influenza strains induced cross-reactive serum antibody to the NA of antigenically distinct $\mathrm{H} 1 \mathrm{~N} 1 / 2009$ pdm, mostly in elderly individuals $[9,10]$.

The aim of our current study was to examine the presence of homologous and cross-reactive NI antibodies against $\mathrm{H} 1 \mathrm{~N} 1 / 2009 \mathrm{pdm}$ in serum samples collected in the fall of 2010 from healthy Russian people for more detailed estimation of the overall and age-specific influenza immunity.

\section{Results and discussion}

We estimated HI and NI antibodies against both H1N1/ 2009pdm and seasonal H1N1/1999 influenza viruses in 163 sera samples obtained in the fall of 2010 (Figure 1). Forty-four of the 163 individuals examined (27\%) had HI H1N1/2009pdm antibody titers $>1: 20$, while 75 (46\%) had HI H1N1/1999 antibody titers $>1: 20$. Also, 93 (57.1\%) of the participants expressed NI H1N1/1999 antibodies in titers $>1: 20$, while only 58 (35.6\%) expressed NI H1N1/2009pdm antibodies in such titers (McNemar test: $\mathrm{p}<0.001)$.

From the 163 examined sera among 39.3\% were detected antibody titers $>1: 20$ against both $\mathrm{HI}$ and $\mathrm{NI}$ of H1N1/1999; $6.7 \%$ and $17.8 \%$ expressed only HI or NI antibodies against $\mathrm{H} 1 \mathrm{~N} 1 / 1999$ in such titers, respectively. In comparison, $17.8 \%$ sera were double-positive to both $\mathrm{H} 1 \mathrm{~N} 1 / 2009$ pdm surface antigens; $9.2 \%$ and $17.8 \%$ expressed only HI- or NI-antibodies against pandemic strain in titers $>1: 20$, respectively. Chi-square test's p-value $<0.001$ suggested a statistically significant relationship between $\mathrm{HI}$ and NI antibody levels against each $\mathrm{A} / \mathrm{H} 1 \mathrm{~N} 1$ in the same serum samples, although the correlation was rather low (Spearman $\mathrm{rs}=0.32$ [95\% CI: $0.11-0.57]$, and $\mathrm{rs}=0.29$ [95\% CI: $0.01-$ $0.54]$, in case of $\mathrm{H} 1 \mathrm{~N} 1 / 1999$ and $\mathrm{H} 1 \mathrm{~N} 1 / 2009 \mathrm{pdm}$ respectively). Forty-eight (29.5\%) of subjects had NI titers > 1:20 against both $\mathrm{H} 1 \mathrm{~N} 1 / 1999$ and $\mathrm{H} 1 \mathrm{~N} 1 /$ 2009pdm [95\% CI: $23.0 \%-36.9 \%$ ].

The age distribution of A/H1N1-specific antibodies was analyzed in several age groups of participants. Persons in group 1 were born prior to 1957; group 2: 1957-1976; group 3: 1977-1999; and group 4, after 2000 (Table 1). Only group 1 expressed NI antibodies against $\mathrm{H} 1 \mathrm{~N} 1 / 2009$ pdm in significantly higher mean titers than HI antibodies (Table 1). The highest mean titers of NI antibodies against both H1N1/2009pdm and $\mathrm{H} 1 \mathrm{~N} 1 / 1999$ were detected in group 3.

Figure 2 presents the seroprotection rates (proportions of subjects with antibody titers $\geq 1: 40$ ) [11] among groups of participants. Again participants in group 3 (1977-1999 years of birth) had the levels of herd immunity to both HA and NA of seasonal H1N1/1999 even higher than children born after 2000 (group 4), when A/New Caledonia/20/99(H1N1) became dominant (Fisher's test: $\mathrm{p}=0.0001$; see Figure 2). This phenomenon could be attributed to higher social
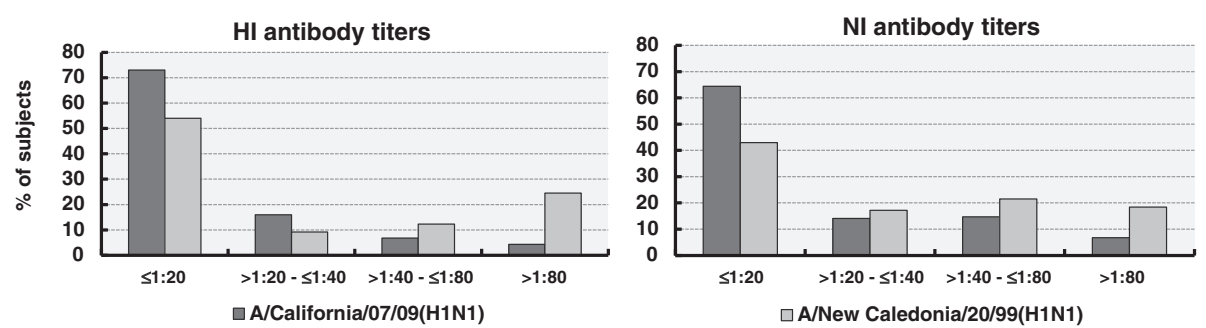

Figure 1 Serum antibody titers against $\mathrm{H} 1 \mathrm{N1} / 1999$ and H1N1/2009pdm in the fall of 2010. Distribution of hemagglutination-inhibition and neuraminidase-inhibition antibody titers against seasonal and pandemic A/H1N1 influenza viruses in serum samples collected from 163 volunteers in the fall of 2010. 
Table 1 Titers of antibodies against A/H1N1 influenza in volunteers of different ages examined in 2010

\begin{tabular}{|c|c|c|c|c|c|}
\hline \multirow[t]{2}{*}{ Groups } & \multirow[t]{2}{*}{ Year of birth } & \multicolumn{2}{|c|}{ Antibodies against H1N1/2009pdm, log2 } & \multicolumn{2}{|c|}{ Antibodies against $\mathrm{H} 1 \mathrm{~N} 1 / 1999, \log 2$} \\
\hline & & HI titers, Me $(\mathrm{Q} 1 ; \mathrm{Q} 3)$ & NI titers, Me (Q1;Q3) & HI titers, Me (Q1;Q3) & NI titers, Me (Q1;Q3) \\
\hline $1(n=24)$ & Before 1957 & $2.3^{1}(2.3 ; 2.3)$ & $3.5(2.3 ; 5.3)$ & $2.3^{2}(2.3 ; 2.8)$ & $3.9(2.3 ; 5.1)$ \\
\hline $2(n=24)$ & 1957-1976 & $2.3(2.3 ; 5.3)$ & $2.3^{3}(2.3 ; 3.3)$ & $2.3(2.3 ; 4.3)$ & $3.8(2.3 ; 4.6)$ \\
\hline $3(n=78)$ & 1977-1999 & $4.3^{4}(3.3 ; 5.3)$ & $4.3(3.4 ; 5.3)$ & $6.3^{5}(5.3 ; 8.3)$ & $5.7^{6}(4.8 ; 6.4)$ \\
\hline $4(n=37)$ & After 2000 & $2.3(2.3 ; 5.3)$ & $2.9(2.3 ; 5.3)$ & $2.3(2.3 ; 5.3)$ & $3.4(2.3 ; 5.3)$ \\
\hline
\end{tabular}

Key: Me (medians), Q1; Q3 (lower and upper quartiles).

${ }^{1}$ Mean titers of $\mathrm{HI}$ antibodies against $\mathrm{H} 1 \mathrm{~N} 1 / 2009 \mathrm{pdm}$ are lower than $\mathrm{NI}$ antibodies $(\mathrm{p}=0.001)$.

${ }^{2}$ Mean titers of $\mathrm{HI}$ antibodies against $\mathrm{H} 1 \mathrm{~N} 1 / 1999$ are lower than $\mathrm{NI}$ antibodies $(\mathrm{p}=0.006)$.

${ }^{3}$ Mean titers of antibodies against NA of pandemic influenza virus H1N1/2009pdm in are lower in group 2 than in group 3 ( $p=0.002$ ).

${ }^{4}$ Mean titers of $\mathrm{HI}$ antibodies against $\mathrm{H} 1 \mathrm{~N} 1 / 2009 \mathrm{pdm}$ are higher in group 3 than in group $1(\mathrm{p}=0.0002)$.

${ }^{5}$ Mean titers of $\mathrm{HI}$ antibodies against $\mathrm{H} 1 \mathrm{~N} 1 / 1999$ are higher in group 3 than in groups 1,2 , and $4(\mathrm{p}<0.0001)$.

${ }^{6}$ Mean titers of $\mathrm{Nl}$ antibodies $\mathrm{H} 1 \mathrm{~N} 1 / 1999$ are higher in group 3 than in groups 1,2 , and $4(\mathrm{p}<0.001)$.

activity of older people from group 3 over young children, leading to more infections and development of cross-reactive antibodies to previously circulating A/ H1N1 influenza viruses.

Participants born between 1957 and 1976 possessed the lowest levels of NI antibodies against both H1N1/ 1999 and H1N1/2009pdm influenza viruses (Table 1, Figure 2).

To determine a possible origin of NI antibodies against $\mathrm{H} 1 \mathrm{~N} 1 / 2009 \mathrm{pdm}$, we evaluated antibody titers $\geq 1: 40$ supposed to be protective in three groups separated on the basis of pre-existing $\mathrm{HI}$ antibody levels against H1N1/ $2009 \mathrm{pdm}$ and seasonal A/H1N1 viruses $(\mathrm{n}=159,4$ sera were excluded from analysis because there was no $\mathrm{HI}$ data with all tested $\mathrm{A} / \mathrm{H} 1 \mathrm{~N} 1$ antigens). Group I were persons with low HI titers $(\leq 1: 10)$ against $\mathrm{H} 1 \mathrm{~N} 1 /$ $2009 \mathrm{pdm}$ and no antibodies to other $\mathrm{A} / \mathrm{H} 1 \mathrm{~N} 1$ viruses ( $\leq 1: 20)$; group II were persons with low HI titers $(\leq 1: 10)$ against $\mathrm{H} 1 \mathrm{~N} 1 / 2009 \mathrm{pdm}$ and positive (HI titers $\geq 1: 40$ ) for any of the other tested $\mathrm{A} / \mathrm{H} 1 \mathrm{~N} 1$ influenza viruses (see Methods); and group III included all persons with HI titers against $\mathrm{H} 1 \mathrm{~N} 1 / 2009 \mathrm{pdm} \geq 1: 20$ (Table 2). Group I subjects, who were negative to all $\mathrm{A} / \mathrm{H} 1 \mathrm{~N} 1$ viruses used in the $\mathrm{HI}$ test, had a higher median age (45 years) than group
II (17 years) and group III (15 years), and a wider variation of age (Kolmogorov-Smirnov's test: $\mathrm{p}<0.005$; see Table 2 ).

Persons seropositive to seasonal A/H1N1 viruses but with low HI titers against H1N1/2009pdm (group II) had significantly higher NI titers against H1N1/2009pdm than unexposed subjects from group I $(\mathrm{p}<0.05)$. Two adults from group II, aged 64 and 56 years, demonstrated 1:40 HI titers against A/Khabarovsk/1/77(H1N1) seasonal influenza virus and $\mathrm{NI}$ antibodies against H1N1/ 2009pdm in titers of 1:696 and 1:180, respectively. These data suggest that exposure to seasonal $\mathrm{A} / \mathrm{H} 1 \mathrm{~N} 1$ viruses may induce cross-reactive NI antibodies against H1N1/ 2009pdm in high titers. Nevertheless, group II contained significantly fewer persons with $\mathrm{NI}$ antibody titers $\geq 1: 40$ against $\mathrm{H} 1 \mathrm{~N} 1 / 2009 \mathrm{pdm}$ than against seasonal $\mathrm{H} 1 \mathrm{~N} 1 /$ 1999 (McNemar test: $\mathrm{p}<0.001$ ).

To reveal true cross-reactive NI antibodies against H1N1/2009pdm, we also investigated levels of antibodies against $\mathrm{H} 1 \mathrm{~N} 1 / 2009 \mathrm{pdm}$ in serum samples collected from 18-20-year-old people in the fall of 2005, long before H1N1/2009pdm arose (Figure 3). None of these subjects had detectable anti-H1N1/2009pdm HI antibodies. Only 7.1\% (4 of 56) had NI antibody titers $>1: 20$ against $\mathrm{H} 1 \mathrm{~N} 1 / 2009 \mathrm{pdm}$ compared to $41.1 \%$ (23
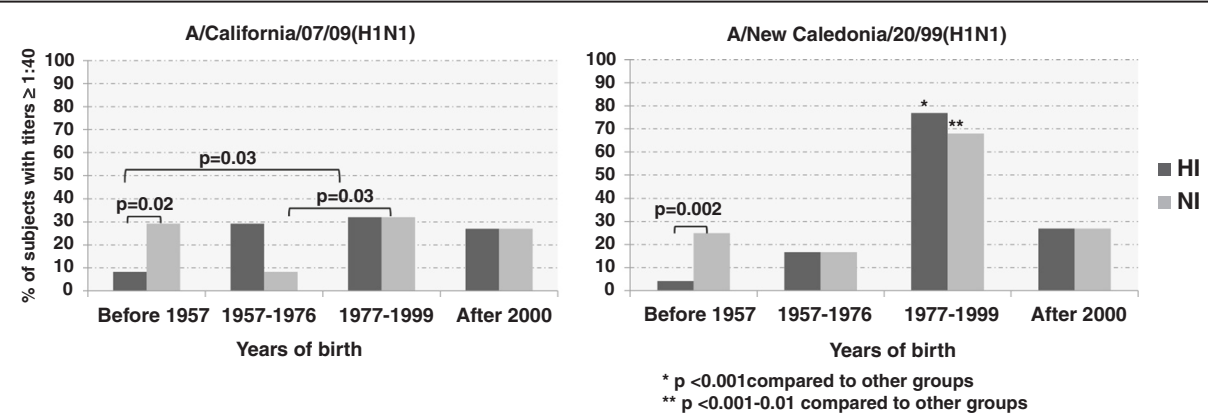

Figure 2 Hemagglutination-inhibition and neuraminidase-inhibition antibodies seroprotection rates in dependence of birth date. Seroprotection rates were defined as a percentage of subjects with titers $\geq 1: 40$ of hemagglutination-inhibition and neuraminidase-inhibition antibodies against H1N1/1999 or H1N1/2009pdm influenza viruses among 163 individuals examined in the fall of 2010. 
Table 2 Homologous and cross-reactive antibodies against NA of H1N1/2009pdm among participants examined in 2010

\begin{tabular}{|c|c|c|c|c|c|c|c|c|c|c|c|}
\hline \multirow[t]{3}{*}{ Group } & \multirow{2}{*}{\multicolumn{2}{|c|}{$\begin{array}{l}\text { HI antibody levels against } A / H 1 N 1 \text { influenza } \\
\text { viruses }\end{array}$}} & \multirow{3}{*}{$\begin{array}{l}\text { Age, } \\
\text { years Me } \\
\text { (Q1;Q3) }\end{array}$} & \multicolumn{4}{|c|}{ Antibodies to $\mathrm{H} 1 \mathrm{~N} 1 / 2009 \mathrm{pdm}$} & \multicolumn{4}{|c|}{ Antibodies to H1N1/1999 } \\
\hline & & & & \multicolumn{2}{|c|}{ HI titers, log2 } & \multicolumn{2}{|l|}{ NI titers, $\log 2$} & \multicolumn{2}{|c|}{ HI titers, log2 } & \multicolumn{2}{|c|}{ NI titers, $\log 2$} \\
\hline & H1N1/2009pdm & seasonal $A / H 1 N 1$ viruses & & Me (Q1;Q3) & $\% \geq 1: 40$ & Me (Q1;Q3) & $\% \geq 1: 40$ & Me $(\mathrm{Q} 1 ; \mathrm{Q} 3)$ & $\% \geq 1: 40$ & Me $(\mathrm{Q} 1 ; \mathrm{Q} 3)$ & $\% \geq 1: 40$ \\
\hline । & $\leq 1: 10$ & $\leq 1: 20$ & $45(6 ; 58)$ & $2.3(2.3 ; 2.3)$ & 0 & $2.3(2.3 ; 3.2)$ & 2.4 & $2.3(2.3 ; 2.3)$ & 0 & $2.3(2.3 ; 4.1)$ & 2.4 \\
\hline \multicolumn{12}{|l|}{$N=41$} \\
\hline$\|$ & $\leq 1: 10$ & $\geq 1: 40$ & $17(10 ; 26)$ & $2.3^{1}(2.3 ; 3.3)$ & 0 & $3.4^{2}(2.3 ; 4.3)$ & 15.7 & $6.2(4.3 ; 8.3)$ & 72.5 & $5.3(4.1 ; 6.2)$ & $51.0^{3}$ \\
\hline \multicolumn{12}{|l|}{$N=51$} \\
\hline III & $\geq 1: 20$ & any & $15(12 ; 20)$ & $5.3(4.3 ; 6.3)$ & 65.7 & $5.2^{4}(3.9 ; 5.6)$ & 38.8 & $5.3(2.3 ; 7.3)$ & 56.7 & $5.5(3.9 ; 6.4)$ & 55.2 \\
\hline$N=67$ & & & & & & & & & & & \\
\hline
\end{tabular}

Key: N (number), Me (medians), Q1; Q3 (lower and upper quartiles); \% (percent).

${ }^{1}$ Titers of $\mathrm{HI}$ antibodies against $\mathrm{H} 1 \mathrm{~N} 1 / 2009 \mathrm{pdm}$ are similar in group I and group II (Dunn's test: $\mathrm{z}^{\prime}=0.959, \mathrm{p}=1.0$ ).

${ }^{2}$ Titers of $\mathrm{Nl}$ antibodies H1N1/2009pdm are higher in group II than in group I (Dunn's test: $z^{\prime}=2.421, p=0.046$ ).

${ }^{3}$ In group II, percentage of volunteers with antibody titers $\geq 1: 40$ to NA of seasonal H1N1/1999 higher than to NA of H1N1/2009pdm (McNemar test: $p<0.001$ ).

${ }^{4}$ Titers of $\mathrm{NI}$ antibodies against H1N1/2009pdm are higher in group III than in group II (Dunn's test: $z^{\prime}=4.043, p=0.0002$ ). 

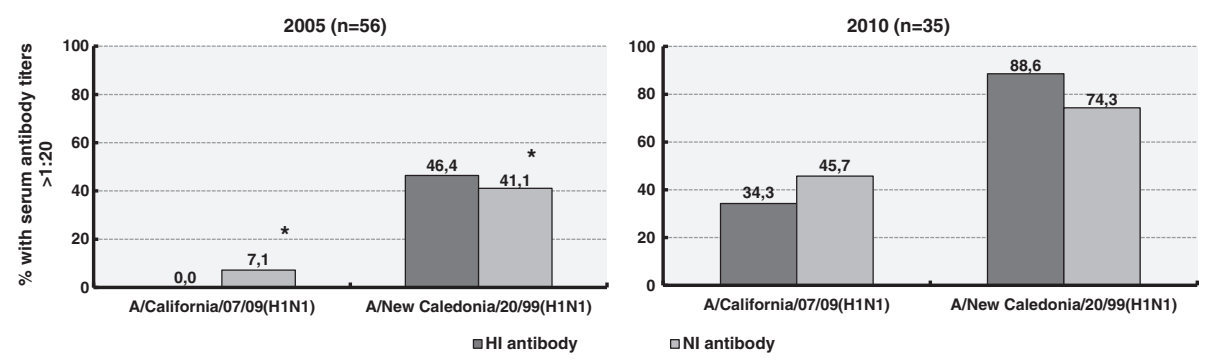

Figure 3 Serum antibodies against A/H1N1 influenza viruses during 2005 and 2010 flu seasons. Percentage of seropositive 18-20-year-old persons with titers $>1: 20$ of hemagglutination-inhibition and neuraminidase-inhibition antibodies against seasonal and pandemic $\mathrm{A} / \mathrm{H} 1 \mathrm{~N} 1$ influenza viruses; * indicates $p<0.001$, McNemar test.

of 56) with $\mathrm{NI}$ antibody titers $>1: 20$ against epidemic H1N1/1999 (McNemar test: $\mathrm{p}<0.001$ ). In contrast, $34.3 \%$ (12 of 35) of samples collected from young adults of the same age in 2010 contained HI antibodies in titers > 1:20 against H1N1/2009pdm, and $45.7 \%$ (16 of 35 ) participants demonstrated NI antibodies to pandemic virus in titers $>1: 20$.

A year after the pandemic A/H1N1 virus first emerged in Russian population the mean titers of specific $\mathrm{HI}$ and NI antibodies against H1N1/2009pdm in all examined volunteers were 2-2.1 times lower than levels of antibodies against H1N1/1999, which circulated in Russia 1999-2006. Likewise Cramer et al. [12] previously reported that in 2010 the threshold level of herd immunity against H1N1/2009pdm was not achieved in Hamburg, Germany.

In our study, the participants born between 1977 and 1999 were the most likely to be infected to pandemic H1N1/2009pdm compared to those born before 1957. This finding confirmed the extensive published data about the high frequency of H1N1/2009pdm infection in children, teenagers, and adults younger than 35 years during the 2009 pandemic, varying between $20-60 \%$ in different countries [13]. High anti-H1N1/2009pdm NA antibody levels, rather than anti-HA antibody levels, in participants older than 53 years can be attributed to contact with earlier circulating A/H1N1 viruses. Examining ages of persons with no antibodies against H1N1/ 2009pdm HA (HI titers $\leq 1: 10$ ), we found anti-H1N1/ 2009pdm NA antibodies in titers $\geq 1: 40$ in $22.7 \%$ (5 of 22), $12.9 \%$ ( 4 of 31 ), and $3.8 \%$ ( 1 of 26 ) of participants born before 1957, in 1977-1999, and after 2000, respectively, but none in persons born between 1957 and 1977. Thus, in our study differences in levels of anti-H1N1/ 2009pdm NA antibodies in people without direct contact with pandemic virus depended on age and, possibly, on priming by previous epidemic influenza viruses. Indeed, volunteers born in 1957-1976, when influenza viruses $\mathrm{A} / \mathrm{H} 2 \mathrm{~N} 2$ and $\mathrm{A} / \mathrm{H} 3 \mathrm{~N} 2$ were circulating, were the least likely to have anti-H1N1/2009pdm NA antibody titers $\geq 1: 40$, but about one third of participants from this age group had anti-H1N1/2009pdm HI antibody titers $\geq 1: 40$ (Figure 2), most likely due to pandemic virus natural infection.

The low correlation between $\mathrm{HI}$ and NI antibody titers we found can be attributed to the autonomy of the serum immune response to both surface glycoproteins of the influenza virus, widely reviewed in scientific literature [14-16]. Other reasons for such divergence may be different times of persistence of NI and HI antibodies, according to individual anamnesis of the surveyed influenza infections $[17,18]$, and the ability of anti-NA antibodies to interact with a wider spectrum of viruses than anti-HI antibodies. Thus, some persons with no antibodies against $\mathrm{HA}$ of influenza pandemic virus in the fall of 2010 still may have been exposed to H1N1/2009pdm. Nevertheless, high levels of antibodies against H1N1/ 2009pdm NA among participants not expressing antiH1N1/2009pdm HA of pandemic virus, but positive to epidemic H1N1 viruses HA, compared with completely negative individuals examined during the same epidemic period, may, to some extent, confirm the relationship between exposure to epidemic $\mathrm{A} / \mathrm{H} 1 \mathrm{~N} 1$ viruses and development of antibodies cross-reactive with H1N1/ 2009 pdm NA. However, the most reliable data about truly cross-reactive antibodies to $\mathrm{H} 1 \mathrm{~N} 1 / 2009 \mathrm{pdm}$ may be obtained using sera collected long before the appearance of pandemic virus. During the 2005 epidemic season, the $7.1 \%$ of the 56 examined in our study 18 20-year-old volunteers had anti-pandemic virus NI antibodies in titers $>1: 20$.

The most convincing data concerning the protective action of pre-existing anti-NA antibodies were obtained in the 1970s using a large cohort of volunteers with no or low levels of anti-HA antibodies against pandemic influenza. One such study, by Monto et al. [8], showed that, prior to the Hong Kong A/H3N2 influenza pandemic, only $12 \%$ of the population had high NI antibody titers to NA of N2 subtype, while $72 \%$ had none. The relatively low level of herd immunity to $\mathrm{A} / \mathrm{H} 2 \mathrm{~N} 2 \mathrm{NA}$ in the population correlated with the wide distribution of the new pandemic subtype A/H3N2 virus in 1968. 
However, this herd immunity was nonetheless sufficient to moderate the severity of the pandemic: the frequency of confirmed A/H3N2 influenza infection, determined by elevated levels of $\mathrm{HI}$ antibodies, was reversely proportional to pre-existing levels of anti-N2 antibodies. The possible effect of HA was eliminated because the sera were obtained before the virus with the novel $\mathrm{H} 3 \mathrm{HA}$ had appeared. Volunteers between 20 and 45 years of age who had anti-N2 antibodies in titers $\geq 1: 16$ were 2.0-2.6-fold less likely to develop respiratory infection symptoms than persons with low NI antibody titers. The authors suggested that neuraminidase antibody can protect not so much against infection as against symptoms of influenza thus permitting the individual to 'up-date' his antibody status from time to time without suffering clinical influenza [8]. The levels of protective NI antibodies still unclear although protective $\mathrm{HI}$ antibody titers defined as $\geq 1: 40$ [11]. The results of several studies suggest the different levels of NI antibodies obtained in several laboratories (1:8- $\geq 1: 20)$ may be protective against natural influenza infection $[8,18,19]$.

\section{Conclusions}

Our study confirmed that contact with seasonal influenza viruses may have contributed to generating the cross-reacting antibodies against NA of H1N1/2009pdm. Indeed, cross-reactive anti-H1N1/2009pdm NA present in the sera of individuals negative to pandemic virus $\mathrm{HA}$, but positive to epidemic strains of A/H1N1 subtype. NI antibodies against the pandemic virus were detected among $7.1 \%$ of volunteers $18-20$ years old examined in 2005 , several years before this virus actually broke out. The lowest levels of antibodies to the NA of N1 subtype belonging to either $\mathrm{H} 1 \mathrm{~N} 1 / 2009$ pdm or $\mathrm{H} 1 \mathrm{~N} 1 / 1999$ were in the group of participants 1957-1977 years of birth, i.e. born during the circulation of influenza $\mathrm{A} / \mathrm{H} 2 \mathrm{~N} 2$ or $\mathrm{A} /$ H3N2 viruses.

The low correlation between $\mathrm{HI}$ and NI antibody titers we found suggests that NI antibody detection can be used as an additional test to evaluate the immune response after influenza infections or immunizations.

\section{Methods \\ Viruses}

The $\mathrm{A} / \mathrm{H} 7 \mathrm{~N} 1$ reassortant influenza virus containing $\mathrm{A} /$ California/07/2009(H1N1) NA and A/equine/Prague/1/ 56(H7N7) HA was generated by classical genetic reassortment in embryonated chicken eggs [20]. Parental A/equine/Prague/1/56(H7N7) influenza virus was kindly provided by Dr. Klimov at the CDC (Atlanta, GA, USA). The other A/H7N1 reassortant influenza virus containing A/New Caledonia/20/1999(H1N1) NA and A/equine/ Prague/1/56(H7N7) HA was provided by the Institute of
Influenza, Ministry of Healthcare of the Russian Federation, Saint Petersburg, Russian Federation.

\section{Serum samples}

163 sera were collected in the fall of 2010 from Russian people aged 2-83 years. Patient history regarding previous influenza infections or vaccinations was unknown. These serum samples left as part of routine tests. We also tested 56 sera left as part of screening tests of young adults examined before vaccination with seasonal influenza vaccine in the fall of 2005.

\section{Ethics statement}

In our retrospective study we used only serum samples left as a part of routine tests. These serum samples were provided by the Diagnostics Laboratories (Saint Petersburg, Russian Federation).

\section{Serum antibody evaluation}

Sera were treated with receptor-destroying enzyme from Vibrio cholerae (Denka-Seiken, Tokyo, Japan), and tested in duplicate for hemagglutination-inhibition H1-specific antibodies using standard procedures [21] with the following test antigens: live influenza vaccine viruses $\mathrm{A} /$ 17/California/09/38(H1N1), A/17/New Caledonia/99/ 145(H1N1), A/17/Solomon Islands/06/9(H1N1), A/17/ Brisbane/07/28(H1N1); seasonal influenza virus 1977 year of isolation $\mathrm{A} /$ Khabarovsk/1/77(H1N1) and A/Puerto Rico/8/34(H1N1).

The peroxidase-linked lectin micro-procedure previously reported by Lambré et al. [22] was adjusted to assay NI antibodies using diagnostic A/H7N1 reassortant viruses. Serum samples were heated at $56^{\circ} \mathrm{C}$ for $30 \mathrm{~min}$, serially diluted in PBS-BSA with the $\mathrm{pH}=6.9$ (typically, seven 2-fold dilutions starting at 1:10). Sixty $\mu \mathrm{L}$ of serum dilutions were incubated with an equal volume of pre-diluted virus containing $128 \mathrm{HA}$ units for $30 \mathrm{~min}$ at $37^{\circ} \mathrm{C}$. After incubation, $100 \mu \mathrm{L}$ of the mixture was added to the 96-well plates (Sarstedt AG \& Co, Nümbrecht, Germany) coated with $150 \mu \mathrm{L}$ of $50 \mu \mathrm{g} / \mathrm{mL}$ fetuin (Sigma-Aldrich, St. Louis, MO, USA). After 2 hours incubation at $37^{\circ} \mathrm{C}$ the plates were washed, and NA activity was measured by incubating with peroxidaselabeled peanut lectin $(2.5 \mu \mathrm{g} / \mathrm{mL}$; Sigma-Aldrich, St. Louis, MO, USA) for $1 \mathrm{~h}$ at room temperature, washing, and adding $100 \mu \mathrm{L}$ of peroxidase substrate. The reaction was stopped after 5 min with $100 \mu \mathrm{L}$ of $1 \mathrm{~N}$ sulfuric acid. OD values were measured at $450 \mathrm{~nm}$ using the universal microplate reader (ELx800, Bio-Tek Instruments Inc, Winooski, VT, USA). NI titers were expressed as the inverse of the dilution that gave 50\% $\mathrm{OD}_{450}$ of positive control (virus without serum). 


\section{Statistical analysis}

Data were analyzed with Statistica software, version 6.0 (StatSoft, Inc. Tulsa, Oklahoma, USA). Medians (Me) and lower and upper quartiles (Q1; Q3) were calculated and used to represent the antibody response. Comparisons of two independent groups were made with nonparametric test, namely the Kolmogorov-Smirnov 2-sample test. To compare multiple independent groups, we used a Kruskal-Wallis analysis of variance (ANOVA) with subsequent multiple pairwise comparisons based on Kruskal-Wallis sums of ranks. Comparisons of two dependent variables were performed using Wilcoxon matched pairs test. In the case of nominal variables, Chisquare tests, Fisher exact 2-tailed tests, or McNemar's chi-square tests were done. Non-parametric measure of statistical dependence between 2 variables was done using Spearman's rank correlation coefficient. The pvalue $\leq 0.05$ was considered to be statistically significant. Additionally, we used the Bonferroni correction for significance levels when testing several hypotheses on a single set of data.

\section{Abbreviations \\ HA: Hemagglutinin; NA: Neuraminidase; HI: Hemagglutination inhibition; NI: Neuraminidase inhibition; Me: Medians; GMT: Geometric mean titers.}

\section{Competing interests}

The authors declare that they have no competing interests.

\section{Authors' contributions}

YAD participated in the design of the study, developed the RN1/09 A/H7N1 reassortant influenza virus and prepared the manuscript. TAS adjusted and performed the NI test and carried out statistical analysis. SAD performed the hemagglutination inhibition test. LGR carried out study coordination and helped to draft the manuscript. All authors read and approved the final manuscript.

\section{Acknowledgements}

This study was supported by the Russian Science Foundation (14-15-00034). The authors acknowledge Dr. Alexander Klimov, Influenza Division, National Center for Immunization and Respiratory Diseases, CDC, Atlanta, GA, USA. We also thank Dr. N.E. Gorev, Institute of Influenza, Saint Petersburg, Russia, for preparing and providing the RN1/99-human A/H7N1 reassortant influenza virus

We also acknowledge Dr. Vadim Tzvetnitsky of PATH for his editorial review.

Received: 6 December 2014 Accepted: 23 March 2015

Published online: 10 April 2015

\section{References}

1. Garten RJ, Davis CT, Russell CA, Shu B, Lindstrom S, Balish A, et al. Antigenic and genetic characteristics of swine-origin 2009 A(H1N1) influenza viruses circulating in humans. Science. 2009;325(5937):197-201.

2. Hancock K, Veguilla V, Lu X, Zhong W, Butler EN, Sun H, et al. Cross-reactive antibody responses to the 2009 pandemic H1N1 influenza virus. N Engl J Med. 2009;361(20):1945-52.

3. Greenbaum JA, Kotturi MF, Kim Y, Oseroff C, Vaughan K, Salimi N, et al. Preexisting immunity against swine-origin $\mathrm{H} 1 \mathrm{~N} 1$ influenza viruses in the general human population. Proc Natl Acad Sci USA. 2009;106(48):20365-70.

4. Bosch BJ, Bodewes R, de Vries RP, Kreijtz JH, Bartelink W, van Amerongen G, et al. Recombinant soluble, multimeric HA and NA exhibit distinctive types of protection against pandemic swine-origin $2009 A(H 1 N 1)$ influenza virus infection in ferrets. J Virol. 2010;84(19):10366-74.
5. Johansson BE, Grajower B, Kilbourne ED. Infection-permissive immunization with influenza virus neuraminidase prevents weight loss in infected mice. Vaccine. 1993;11(10):1037-9.

6. Sandbulte MR, Jimenez GS, Boon AC, Smith LR, Treanor JJ, Webby RJ. Crossreactive neuraminidase antibodies afford partial protection against $\mathrm{H} 5 \mathrm{~N} 1$ in mice and are present in unexposed humans. PLoS Med. 2007:4(2):265-72.

7. Schulman JL, Khakpour M, Kilbourne ED. Protective effects of specific immunity to viral neuraminidase on influenza virus infection of mice. J Virol. 1968;2(8):778-86.

8. Monto AS, Kendal AP. Effect of neuraminidase antibody on Hong Kong influenza. Lancet. 1973;1 (7804):623-5.

9. Cate TR, Rayford Y, Nino D, Winokur P, Brady R, Belshe R, et al. A high dosage influenza vaccine induced significantly more neuraminidase antibody than standard vaccine among elderly subjects. Vaccine. 2010;28(9):2076-9.

10. Marcelin G, Bland HM, Negovetich NJ, Sandbulte MR, Ellebedy AH, Webb $A D$, et al. Inactivated seasonal influenza vaccines increase serum antibodies to the neuraminidase of pandemic influenza A(H1N1) 2009 virus in an age-dependent manner. J Infect Dis. 2010;202(11):1634-8.

11. Nauta JJP, Beyer WEP, Osterhaus ADME. On the relationship between mean antibody level, seroprotection and clinical protection from influenza. Biologicals. 2009:37:216e221. http://www.researchgate.net/profile/ Jozef_Nauta/publication/24184169_On_the_relationship_between_ mean_antibody_level_seroprotection_and_clinical_protection_from_ influenza/links/5433f8790cf2dc341daf0eab.pdf.

12. Cramer J, Mac T, Hogan B, Stauga S, Eberhardt S, Wichmann O, et al. Influenza A(H1N1)pdm09 antibodies after pandemic and trivalent seasonal influenza vaccination as well as natural infection in November 2010 in Hamburg, Germany. Euro Surveill. 2012;17(2):20052.

13. Broberg E, Nicoll A, Amato-Gauci A. Seroprevalence to influenza A(H1N1) 2009 virus -where are we? Clin Vaccine Immunol. 2011;18(8):1205-12.

14. Jennings R, Potter CW, Massey PM, Duerden BI, Martin J, Bevan AM. Responses of volunteers to inactivated influenza virus vaccines. J Hyg (Lond). 1981;86(1):1-16

15. Kendal AP, Bozeman FM, Ennis FA. Further studies of the neuraminidase content of inactivated influenza vaccines and the neuraminidase antibody responses after vaccination of immunologically primed and unprimed populations. Infect Immun. 1980;29(3):966-71.

16. Kilbourne ED. Comparative efficacy of neuraminidase-specific and conventional influenza virus vaccines in induction of antibody to neuraminidase in humans. J Infect Dis. 1976;134(4):384-94.

17. Schild GC. Antibody against influenza A2 virus neuraminidase in human sera. J Hyg (Lond). 1969;67(2):353-65.

18. Smith AJ, Davies JR. Natural infection with influenza A (H3N2). The development, persistence and effect of antibodies to the surface antigens. J Hyg (Lond). 1976;77(2):271-82.

19. Murphy BR, Kasel JA, Chanock RM. Association of serum anti-neuraminidase antibody with resistance to influenza in man. N Engl J Med. 1972;286 (25):1329-32.

20. Desheva Y, Smolonogina T, Rudenko L. Detection of anti-neuraminidase antibody in preclinical and clinical studies of live influenza vaccine. Influenza Other Respir Viruses. 2011;5 Suppl 1:370.

21. Webster RG, Cox N.J, Stohr K. WHO manual on animal influenza diagnosis and surveillance. World Health Organization, Geneva, Switzerland. 2002. http://www.who.int/csr/resources/publications/influenza/ whocdscsincs20025rev.pdf.

22. Lambré CR, Terzidis H, Greffard A, Webster RG. Measurement of antiinfluenza neuraminidase antibody using a peroxidase-linked lectin and microtitre plates coated with natural substrates. J Immunol Methods. 1990;135(1-2):49-57. 